\title{
Integration of Mobile Learning into Complex Problem-Solving Processes During STEM Education
}

\author{
https://doi.org/10.3991/ijim.v14i21.18463 \\ Elena Shchedrina $\left({ }^{\varpi}\right)$ \\ Russian State Agricultural University, Moscow, Russia \\ shchedrinael54@rambler.ru / shchedrina@rgau-msha.ru \\ Elena Galkina \\ I.M. Sechenov First Moscow State Medical University, Moscow, Russia \\ Irina Petunina \\ “Kuban State Agrarian University named after I.T. Trubilin”, Krasnodar, Russia \\ Richard Lushkov \\ I.M. Sechenov First Moscow State Medical University, Moscow, Russia
}

\begin{abstract}
Over the past few years, the teaching process has transformed radically under significant investments in information and communication technologies. In this context, mobile technologies emerge as an innovative educational tool. Mobile devices are being used by a vast number of so-called "digital generation" representatives in daily life and educational activities. It has been proven that the implementation of mobile technologies in education contributes to the increase of students' motivation, participation in the learning process, and faster acquisition of professional competencies. These technologies take the role of the "driving force" in training. However, their comprehensive understanding is essential to use them effectively. The objective of this study was to analyze the intensity of mobile technologies' use and investigate their evolution in higher education using the example of the I.M. Sechenov First Moscow State Medical University. The research sample was represented by 151 students (data collected for 2015/2016) and 274 students (data for 2019/2020). The average participants' age corresponded to 19.8. The study also involved three experts who were required to evaluate questionnaires completed in Google Forms. The scientific method of the study was based on the organized examination, strict control over the involved respondents, and quantitative research. The research outcomes were analyzed through Chi-Square goodness-of-fit test. The target questions of the survey were rated on a 5-point Likert scale. According to the study results, $95 \%$ of the respondents used mobile devices for educational purposes, of which $65 \%$ agreed with the convenience of having course materials on a mobile device. In the 2015/2016 academic year, the share of students using smartphones for learning comprised $10.4 \%$, while in $2019 / 2020$, their percentage increased to $61.5 \%$. The study findings will be useful for university teachers and representatives of educational institutions' administration.
\end{abstract}

Keywords-Mobile learning, mobile technology, personalized learning, smartphone, tablet 


\section{Introduction}

Rapid technological progress and globalization have changed everyday life at both individual and social levels [1]. In recent years, the introduction of smartphones, tablets, laptops, and online applications in education has become an integral part of the lives of teachers and students. The emergence of new Internet technologies has supported further development of e-learning, thereby changing the nature of higher education [2]. Several decades ago, technological improvements made their way into classrooms through the introduction of online education and the widespread use of information and communication technologies (ICT). With recent advances in the capabilities of smart mobile devices and their growing penetration rate among the student cohort, it is possible to take advantage of these devices to design appropriate exercises and tools that foster student's knowledge and learning [3]. As a result, teachers and researchers are faced with the urgent task of examining how mobile technologies can promote effective learning [4].

However, the scope and implications of the introduction of e-learning and mobile learning (m-learning) are not sufficiently understood and studied since practice, in this case, is ahead of theory. M-learning represents a ubiquitous, wireless, highly portable technology that is endowed with multimedia capabilities and brings a new dimension to curriculum delivery [3]. During the last few years, the introduction of m-learning in schools has become more widespread even though they were primarily designed for non-educational environments. The versatility of the use of mobile devices for educational purposes has aroused considerable interest in the educational community. Researchers confirm the benefits of student-generated multimedia content created during m-learning [5]. Besides, they note that $\mathrm{m}$-learning through student-generated content can be applied during the study of subjects requiring specialized knowledge, like science, technology, engineering, and mathematics (STEM). Such content can be quickly delivered through already available technologies, in particular, mobile platforms that provide wide-ranging and varied coverage of learners.

Each new version of these devices brings innovative features that make them more convenient and affordable. These days, new applications for smartphones and tablets are continually appearing. As a result, there is great potential in using mobile devices to transform the way of learning by changing the traditional classroom to one that is more interactive and engaging. Such an approach allows educators to teach without being restricted by time and place, enabling learning to continue after the lesson is over or outside the classroom. It also gives teachers the ability to connect with learners on a more personal level with devices that they use on a regular basis [3].

Moreover, m-learning allows students to engage in problem-based learning activities, work on goal-oriented tasks, and develop their own understanding through active involvement and sense-making. Thus, learning experiences like digital simulations or manipulations can bring interactivity, enhancing cognitive and affective processes. One of the significant advantages of mobile devices is that students learn to study in new contexts, for example, visiting "virtual" museums or galleries, visualizing experiments in laboratories, etc. Hence, the phenomenon of m-learning is a critical issue requiring particular attention from academicians [6]. 
Most of the studies on online and mobile learning focus on their adoption [7], as well as challenges and opportunities associated with their implementation in the educational process. Only a few scientific papers concentrate on introducing mobile technologies into the training process and the perception of m-learning in terms of its potential. For this reason, the present investigation aims to analyze the intensity and evolution of mobile technologies application in higher education, using the example of I.M. Sechenov First Moscow State Medical University.

\subsection{Electronic and mobile learning in higher education}

Despite its relatively recent appearance in the scientific literature, the concepts of elearning and $\mathrm{m}$-learning have triggered discussions regarding their usefulness in higher education, particularly in developing learning strategies and modernizing the training process. As noted, the practice has understandably run well ahead of theory, and in some issues and approaches away from theory, for example, in the use of virtual learning environments (VLEs) and applications to support them in mobile devices. VLE is defined as a set of teaching and learning tools designed to enhance a student's learning experience by including computers and the Internet in the learning process [8]. The main components of VLE include curriculum, student tracking, online support for both teacher and learner, electronic communication (email, chat, Web publishing), and Internet links to outside curriculum resources. An important event in recent-year education is an intensive introduction of tablets, smartphones, and e-books, which can be called an integral part of m-learning pedagogy. The optimization of mobile devices is also taking a prominent place in the digitalization of university libraries. Now students need to spend less time in the library or borrow books since virtual and electronic archives allow access to content anywhere and anytime. Thus, the functionality, portability, and completeness of online materials greatly facilitate the learning process [9]. The use of mobile devices provides students with a learning experience that is different from gained during e-learning. In the course of m-learning, the training process is carried out in a fundamentally new educational environment.

The main disadvantage of traditional e-learning [7] is that it requires the use of personal computers or laptops, which affects convenience. Today, mobile technologies are so pervasive that they are changing the way people access the bulk of information. The present-day education is on the way of implementing new applications that do not just copy and expand old sources such as books or workbooks but contribute to the development of digital experiences, as well as cognitively active, meaningful, interactive, and social learning. One of the advantages of using m-learning is the effectiveness and convenience of mobile devices. Given their small size, one can study in any convenient place and do it as comfortably as possible, with a flexible schedule and reduced training time. These benefits provide opportunities for m-learning development and its further implementation in education [10].

M-learning can be considered a new expanded e-learning phase that is performed using mobile devices [11]. Several researchers state that the main characteristics of $\mathrm{m}$ learning are mobility, wireless Internet connectivity, and ubiquity [12], and highlight the difference between traditional and m-learning (Table 1). 
Table 1. Difference between traditional education and m-learning

\begin{tabular}{|l|l|}
\hline \multicolumn{1}{|c|}{ Traditional Learning } & \multicolumn{1}{c|}{ M-learning } \\
\hline $\begin{array}{l}\text { Individual assessment, group projects, group discus- } \\
\text { sions and project presentations are carried through } \\
\text { in-class quizzes and tutorials }\end{array}$ & $\begin{array}{l}\text { The use of multimedia elements in conveying infor- } \\
\text { mation. Students can receive online feedback }\end{array}$ \\
\hline $\begin{array}{l}\text { Students should go to a class to attend a lecture, sem- } \\
\text { inar, or practical lesson }\end{array}$ & $\begin{array}{l}\text { The learning process can be done anywhere and at } \\
\text { any time }\end{array}$ \\
\hline $\begin{array}{l}\text { Students should interact face to face in order to study } \\
\text { effectively }\end{array}$ & $\begin{array}{l}\text { Meetings of all students in the group can be orga- } \\
\text { nized at the same time }\end{array}$ \\
\hline $\begin{array}{l}\text { Use of chalk and talk method in delivering infor- } \\
\text { mation }\end{array}$ & $\begin{array}{l}\text { Students can get the lecture notes quickly without } \\
\text { copying from the board }\end{array}$ \\
\hline
\end{tabular}

Source: based on data retrieved from [13]

In general, m-learning is defined as a subset of e-learning, which refers to the use of computer network technology to deliver information and instructions to individuals through the Internet [14]. In recent years, researchers have developed online and mobile applications to support teaching in Algebra, Geometry, Mathematical Analysis, Statistics, and other mathematics areas. Mobile applications allow users to explore functions, providing graphical capabilities, train professional skills, and generate new knowledge [4]. M-learning also facilitates designs for learning that targets real-world problems and involves projects of relevance and interest to the student. Mobile devices allow learners to customize the transfer and access to information to build on their skills and knowledge and meet their own educational goals. In such a manner, m-learning approaches make learner-centered education possible [15]. At the same time, m-learning is divided into three main types: formal (in the class), informal (outside the class), and self-directed (life experience; receiving additional information in courses or through the study of Internet sources).

An important aspect of m-learning is mobile technology. It is a revolutionary communication and information technology designed to meet students' individual information needs [16]. The unique features of new mobile technologies and the unlimited potential they offer in terms of flexibility and adaptability to consumer-driven demands allow knowledge delivery and learning outside of traditional classrooms [7]. Although, in higher education, students are regarded as pioneers in forcing the faculty to change and adapt m-learning [17]. The literature suggests that there are several factors that influence readiness for m-learning. Among them are demographic determinants, technology acceptance, ease of use, perceived usefulness, quality of services, and cultural factors.

As already emphasized, the efficient m-learning environment is crucial for providing effective training. Simultaneously, technologies that should be used in m-learning must have certain components (Fig. 1). 


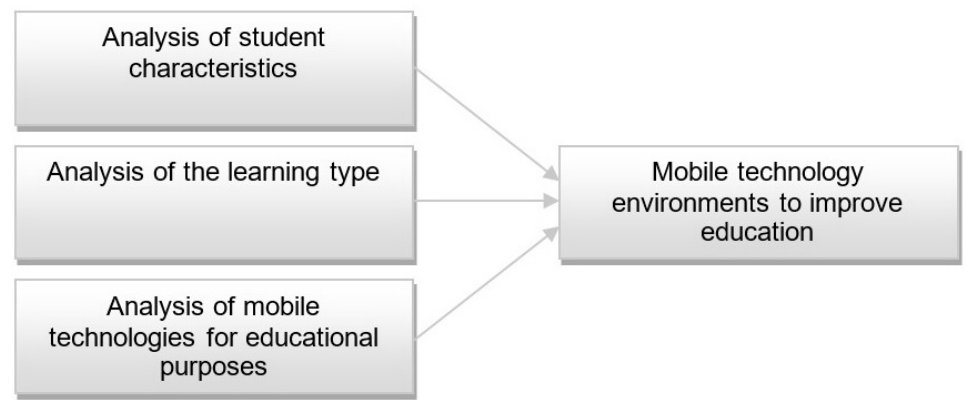

Fig. 1. Components of an m-learning environment

Source: based on data retrieved from [18]

A critical question from the point of view of practicality for users is to organize mobile learning in such a way that students do not get lost in hyperspace while accessing the necessary data. Considering this, researchers suggest several methods to use mobile technologies in the class $[16,18,19]$ :

1. Audio Recording: Students are required to provide personal and quality feedback on the completed work. Mobile technology makes it possible to use the audio recording function built into smartphones. It is often more convenient for students to perceive feedback that was received not in front of his/her groupmates, but through a personal message that can be listened to several times.

2. Survey: Digital survey tools can be used for a formative assessment of knowledge to determine what students already know and what to focus on. The survey method can also provide an insight into individual student strengths and weaknesses and assist in giving personalized instruction when needed.

3. Video: Writing an essay is often accompanied by thoughtless copying of paragraphs without understanding the content. This task can be replaced with the creation of a short video about the student's research results.

4. Chats and discussion forums: The group chat features of mobile devices can be used to create an online discussion forum to encourage participation in learning outside the class.

5. Quick response codes (QR codes): The teacher can provide links to additional resources, diagrams, graphs, images, or solutions to tasks.

\subsection{Mobile learning and STEM}

In recent years, more and more attention has been paid to STEM education. The acronym STEM (Science, Technology, Engineering, and Mathematics) has entered the agenda of educational policies, thereby provoking the identification of the most notable and emerging issues, trends, and challenges in STEM education for the coming years [20]. The focus of STEM is driving ICT in the economy based on knowledge through innovation and productivity, as well as preparing individuals to function in a science and technology-rich society [21]. STEM is the purposeful 
integration of various disciplines to solve real-life problems that involve science, technology, engineering, and mathematics as one unit. It can occur in many general, career, and technical education subject areas such as agriculture, science, health, technology and engineering, and family and consumer science [22]. The STEM approach to learning aims to enrich students' knowledge and improve skills in career development [23]. It contributes to student achievement, scientific and technological literacy, and can provide an understanding of challenging issues through hands-on and mental activities $[24,25]$.

Many researchers argue that STEM can be improved through the use of mobile devices, as there is a tendency according to which the way of teaching in STEM affects students' success. It has been determined [26] that STEM implementation depends on internal and external support factors, including the interactivity of m-learning applications that improve information search and literacy among students and teachers [25]. The emergence of new educational technologies such as m-learning gives the hope that students will become more motivated to study STEM. Studies on the analysis of students' experience in mobile STEM learning reveal an increase in education quality, motivating learners to master STEM disciplines [27]. Researchers propose combining $\mathrm{m}$-learning and STEM capabilities through the use of case studies in practice to provide unique and effective teaching and learning [28]. Scholars consider the early exposure to STEM learning opportunities important since the development of STEM skills can enhance students' interest and educational attainment in STEM, expanding their future career choices. Smart mobile devices have become widespread, and now they are transforming educational practices almost all over the world. In the meantime, there is evidence that teacher education departments lack the experience to teach other instructors about using these devices in their daily professional practice. Scholars underline the need to develop teaching and learning processes that go beyond a mere transmission of the technical knowledge required to use mobile technologies for educational purposes. Instead, they focus on raising students' awareness about the educational benefits that the integration of mobile technologies can bring to traditional education [29]. However, there is a strong opinion that such technologies are to be implemented in STEM to improve learning outcomes [21].

\section{$2 \quad$ Methodology}

The current study included organized investigation, control over the involved respondents, and quantitative research methodology. The data collected for the quantitative survey were accompanied by appropriate statistical analysis to verify the obtained study results.

\subsection{Research sample}

The study involved students from I.M. Sechenov First Moscow State Medical University (Sechenov University) - the oldest medical school in Russia. The research sample consisted of 151 people who took part in the research conducted during the 
2015/2016 academic year, and 274 people who were enrolled in the study during the 2019/2020 academic session. The involved participants were undergoing Bachelor's degree programs in the specialties Management, Mechanics and Mathematical Modeling, and Intelligent Systems in Humanities. For both academic years under consideration, the average respondents' age constituted 19.8 years, while the gender distribution was represented by approximately $60 \%$ of female learners and approximately $40 \%$ of male students.

The examination also involved three experts in the field of pedagogy and ICT, who analyzed the completed questionnaires. The group of respondents was formed on a voluntary basis. Invitations to participate in the study were sent via e-mail, while the data for consideration were obtained by filling out corresponding questionnaires in Google Forms.

\subsection{Research design}

As an illustrative example, the Results section includes an analysis of the questions that were noted as decisive by the experts. The choice of the quantitative research methodology can be explained by the fact that it allows determining respondents' opinions and positions based on a structured questionnaire, uniform compression of respondents' data, and standardization of results.

This research included several stages. The first part of the examination process was performed during the 2019/2020 academic year to determine whether m-learning and mobile technologies are suitable for the educational process from the students' point of view. The survey covered 274 respondents who could choose several options of the proposed answers in the process of filling out an online questionnaire in Google Forms. The survey included only two questions (statements):

Statement 1 - I believe that access to educational materials via mobile devices has advantages for the educational process;

Statement 2 - I believe that m-learning can increase the overall course achievements.

The target statements were supposed to be rated on a 5-point Likert scale [30], where:

1. Point - fully disagree

2. Points - partially disagree

3. Points - not sure

4. Points - partially agree

5. Points - fully agree.

The second research stage consisted of collecting and analyzing data concerning the evolution and dynamics of the use of mobile devices in the learning process through the questionnaire method. The information for the comparison was obtained during the 2015/16 and 2019/20 academic courses.

The third stage included the analysis and processing of data collected after surveying students who studied during the 2019/2020 academic year concerning the degree of use of mobile devices in the educational process. This analysis was performed by specialties. 
Within the investigation, Chi-Square goodness-of-fit test was applied. It is a nonparametric test that was used to find out how the observed value of a given phenomenon is significantly different from the expected value [31].

\subsection{Ethical issues}

Each participant was aware of the study process and thus consented to the collecting and processing of personal data. Information about the individual achievements of each respondent was confidential and was not disclosed.

\section{$3 \quad$ Results}

A quantitative analysis of the survey results revealed that $95 \%$ of students use mobile devices for educational purposes. At the same time, $98 \%$ of those surveyed stated that they use mobile devices for at least 120 minutes per day (Fig. 2).

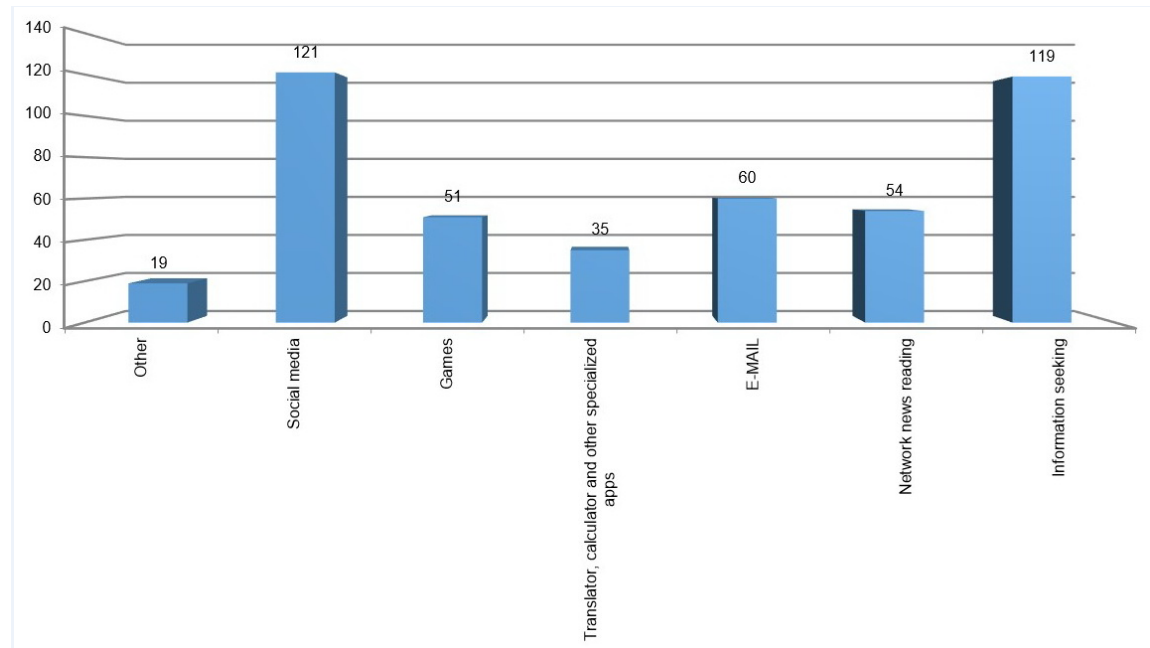

Fig. 2. Mobile device usage statistics

Source: developed by the authors.

The analysis of the survey results also showed that the majority of students highly appreciate the following m-learning advantages:

- Free access to educational materials;

- Ability to interact with other members of the study group;

- High mobility of devices.

The survey outcomes demonstrating the students' opinion concerning Statement 1 are presented in Fig. 3. 


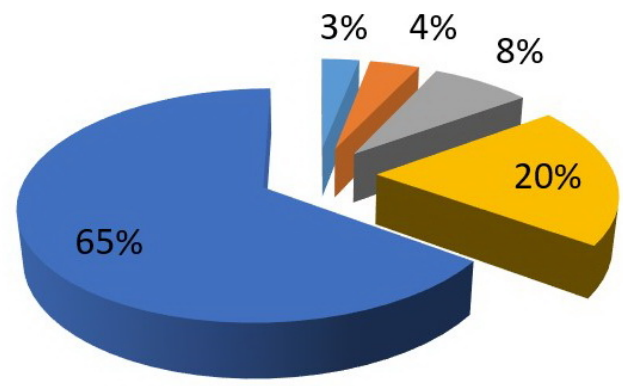

घully disagree $\quad$ Partially disagree $\quad$ Not sure $\quad$ Partially agree $\quad$ Fully agree

Fig. 3. The students' opinion regarding the statement that access to learning materials via mobile devices benefits education

Source: developed by the authors.

It should be noted that $65 \%$ of the surveyed agreed that the availability of study materials (lectures, additional literature, notes, tests, seminars) on a mobile device is beneficial for the educational process.

The questionnaire also provides a statement that m-learning can increase overall achievements in the study course. Respondents' feedback concerning this assumption is displayed in Fig. 4.

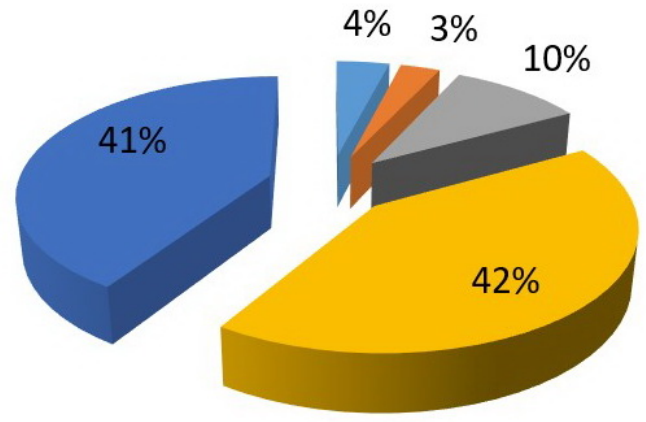

Eully disagree $\quad$ Partially disagree $\quad$ Not sure $\quad$ Partially agree $\quad$ Fully agree

Fig. 4. The students' opinion regarding the statement that m-learning can increase academic performance

Source: developed by the authors.

It is also noteworthy that only $41 \%$ admitted that the use of mobile technologies in teaching could contribute to the improvement of academic achievements within the 
course. Another $42 \%$ of respondents took a somehow uncertain position on this issue and agreed only partially.

Distribution of students by the courses Management, Mechanics and Mathematical Modeling, and Intelligent Systems in Humanities is presented in Fig. 5 for both reviewed academic periods separately.
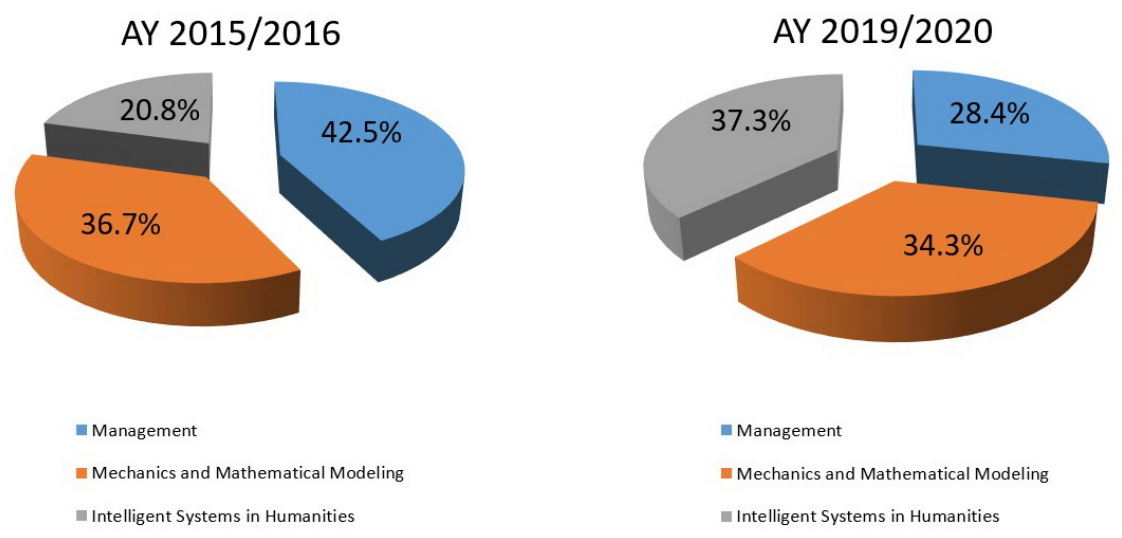

Fig. 5. Distribution of students for each course in the academic years $2015 / 2016$ and $2019 / 2020$

Source: developed by the authors.

During the second stage of the study, a clear trend towards the use of mobile devices in the learning process was revealed (Fig. 6).

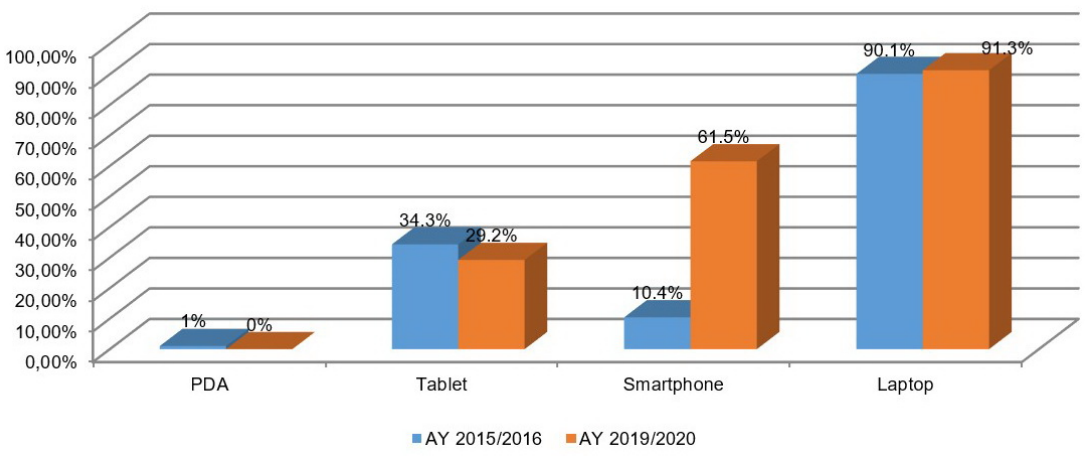

Fig. 6. Frequency of using mobile devices during learning

Source: developed by the authors.

Note: students could choose several of the suggested answers.

In the 2015/2016 academic year, there was practically no dependence between the student's gender or specialty and the tendency to using mobile devices for learning 
purposes. Nevertheless, the calculation of the Chi-Square goodness-of-fit test with correction of continuity for tables $2 \times 2$ led to the conclusion that, depending on gender, there are differences in the students' use of smartphones and tablets in the 2019/2020 academic year (Tables 2-5). It was uncovered that female learners more often use smartphones and tablets than male ones ( $\mathrm{p}$-values $=.034<.05$ and $.013<.05$, respectively).

Table 2. Percentage of smartphone users by gender for AY 2019/2020

\begin{tabular}{|l|c|c|c|}
\hline \multirow{4}{*}{ Gender } & Smartphone Use & & \\
\hline \multirow{3}{*}{ Female } & Yes & No & Total \\
\hline \multirow{3}{*}{ Male } & 106 & 60 & 166 \\
\cline { 2 - 4 } & $63.8 \%$ & $37.2 \%$ & $100 \%$ \\
\cline { 2 - 4 } & $67 \%$ & $53.1 \%$ & $61.2 \%$ \\
\hline \multirow{3}{*}{ Total } & 55 & 53 & 108 \\
\cline { 2 - 4 } & $50.9 \%$ & $49.1 \%$ & $100 \%$ \\
\cline { 2 - 4 } & $33 \%$ & $46.9 \%$ & $38.8 \%$ \\
\hline & 161 & 113 & 274 \\
\cline { 2 - 4 } & $59.1 \%$ & $40.9 \%$ & $100 \%$ \\
\cline { 2 - 4 } & $100 \%$ & $100 \%$ & $100 \%$ \\
\hline
\end{tabular}

Source: developed by the authors.

Table 3. Percentage of tablet users by gender for AY 2019/2020

\begin{tabular}{|l|c|c|c|}
\hline \multicolumn{4}{|c|}{ Tablet Use } \\
\hline \multirow{3}{*}{ Gender } & Yes & No & Total \\
\hline \multirow{3}{*}{ Female } & 115 & 51 & 166 \\
\cline { 2 - 4 } & $69.2 \%$ & $30.8 \%$ & $100 \%$ \\
\cline { 2 - 4 } & $67.8 \%$ & $51.2 \%$ & $61.2 \%$ \\
\hline \multirow{3}{*}{ Male } & 57 & 51 & 108 \\
\hline \multirow{3}{*}{ Total } & $53.5 \%$ & $46.5 \%$ & $100 \%$ \\
\cline { 2 - 4 } & $32.2 \%$ & $48.8 \%$ & $38.8 \%$ \\
\hline & 172 & 102 & 274 \\
\cline { 2 - 4 } & $62.8 \%$ & $38.2 \%$ & $100 \%$ \\
\cline { 2 - 4 } & $100 \%$ & $100 \%$ & $100 \%$ \\
\hline
\end{tabular}

Source: developed by the authors.

Table 4. Chi-Square goodness-of-fit test for gender variable, smartphone use (AY 2019/2020)

\begin{tabular}{|l|c|c|c|}
\hline & Value & df & Asymp. Sig. (2-sided) \\
\hline Pearson's Chi-Square & 5.024 & 1 & .026 \\
\hline Continuity Correction & 4.469 & 1 & .033 \\
\hline
\end{tabular}

Source: developed by the authors. 
Table 5. Chi-Square goodness-of-fit test for gender variable, tablet use (AY 2019/2020)

\begin{tabular}{|l|c|c|c|}
\hline & Value & df & Asymp. Sig. (2-sided) \\
\hline Pearson's Chi-Square & 6,833 & 1 & .008 \\
\hline Continuity Correction & 6,172 & 1 & .014 \\
\hline
\end{tabular}

Source: developed by the authors.

In the course of the investigation, the authors noted statistically significant differences $(p$-value $=.000<.05)$ on the course that the student attends and the use of mobile devices among the respondents of the 2019/2020 academic year (Table 6).

Table 6. Chi-Square goodness-of-fit test for specialty variable, laptop use (AY 2019/2020)

\begin{tabular}{|l|c|c|c|}
\hline & Value & df & Asymp. Sig. (2-sided) \\
\hline Pearson's Chi-Square & 32.088 & 2 & .000 \\
\hline Likelihood Ratio & 36.551 & 2 & .000 \\
\hline Linear-by-Linear Association & 9.201 & 1 & .002 \\
\hline N of Valid Cases & 274 & & \\
\hline
\end{tabular}

Source: developed by the authors.

What is interesting is that students studying Mechanics and Mathematical Modeling use laptops for formal and informal education more often than those who study Intelligent Systems in Humanities and Management (Table 7).

Table 7. Chi-Square goodness-of-fit test for specialty variable, laptop use (AY 2019/2020)

\begin{tabular}{|c|c|c|c|}
\hline \multicolumn{4}{|c|}{ Laptop Use } \\
\hline Specialty & Yes & No & Total \\
\hline \multirow{3}{*}{ Mechanics and Mathematical Modeling } & 3 & 97 & 100 \\
\hline & $3 \%$ & $97 \%$ & $100 \%$ \\
\hline & $5.8 \%$ & $43.2 \%$ & $36.4 \%$ \\
\hline \multirow{3}{*}{ Management } & 34 & 60 & 94 \\
\hline & $34.8 \%$ & $65.2 \%$ & $100.0 \%$ \\
\hline & $64.8 \%$ & $27.6 \%$ & $34.5 \%$ \\
\hline \multirow{3}{*}{ Intelligent Systems in Humanities } & 16 & 64 & 80 \\
\hline & $19.1 \%$ & $88.9 \%$ & $100 \%$ \\
\hline & $29.4 \%$ & $29.2 \%$ & $29.1 \%$ \\
\hline \multirow{3}{*}{ Total } & 53 & 221 & 274 \\
\hline & $19.4 \%$ & $80.6 \%$ & $100 \%$ \\
\hline & $100 \%$ & $100 \%$ & $100 \%$ \\
\hline
\end{tabular}

Source: developed by the authors.

Moreover, it was remarked that Management students use smartphones much more often than other respondents of the study sample. Analysis by Chi-Square goodness-offit test unveiled that there were statistically significant differences in the dependence of the smartphone use on the specialty $(p-v a l u e=.000<.05)($ Tables $8-9)$. 
Table 8. Chi-Square goodness-of-fit test for specialty variable, smartphone use (AY 2019/2020)

\begin{tabular}{|l|c|c|c|}
\hline & Value & df & Asymp. Sig. (2-sided) \\
\hline Pearson's Chi-Square & 32.090 & 2 & .000 \\
\hline Likelihood Ratio & 36.554 & 2 & .000 \\
\hline Linear-by-Linear Association & 9.201 & 1 & .002 \\
\hline N of Valid Cases & 274 & & \\
\hline
\end{tabular}

Source: developed by the authors.

Table 9. Chi-Square goodness-of-fit test for specialty variable, smartphone use (AY 2019/2020)

\begin{tabular}{|l|c|c|c|}
\hline \multicolumn{4}{|c|}{ Smartphone Use } \\
\hline Specialty & Yes & No & Total \\
\hline \multirow{3}{*}{ Mechanics and Mathematical Modeling } & 73 & 26 & 100 \\
\cline { 2 - 4 } & $73.7 \%$ & $26.3 \%$ & $100 \%$ \\
\cline { 2 - 4 } & $45.3 \%$ & $23.2 \%$ & $36.3 \%$ \\
\hline \multirow{3}{*}{ Management } & 34 & 45 & 79 \\
\cline { 2 - 4 } & $43 \%$ & $57 \%$ & $100 \%$ \\
\cline { 2 - 4 } Intelligent Systems in Humanities & $21.1 \%$ & $40.2 \%$ & $28.9 \%$ \\
\hline \multirow{3}{*}{ Total } & 54 & 41 & 80 \\
\cline { 2 - 4 } & $43.1 \%$ & $58.9 \%$ & $100 \%$ \\
\cline { 2 - 4 } & $33.6 \%$ & $36.6 \%$ & $34.8 \%$ \\
\hline & 161 & 113 & 274 \\
\cline { 2 - 4 } & $19.4 \%$ & $80.6 \%$ & $100 \%$ \\
\cline { 2 - 4 } & $100 \%$ & $100 \%$ & $100 \%$ \\
\hline
\end{tabular}

Source: Developed by the authors.

What is more, the examination figured out a clear predominance of the use of tablets for education by respondents engaged in Intelligent Systems in Humanities course ( $p=$ $.003)$. Corresponding data are presented in Tables 10-11.

Table 10. Chi-Square goodness-of-fit test for specialty variable, tablet use (AY 2019/2020)

\begin{tabular}{|l|c|c|c|}
\hline & Value & df & Asymp. Sig. (2-sided) \\
\hline Pearson's Chi-Square & 14.167 & 3 & .003 \\
\hline Likelihood Ratio & 13.982 & 3 & .003 \\
\hline Linear-by-Linear Association & 8.362 & 1 & .004 \\
\hline N of Valid Cases & 274 & & \\
\hline
\end{tabular}

Source: developed by the authors. 
Table 11. Chi-Square goodness-of-fit test for specialty variable, tablet use (AY 2019/2020)

\begin{tabular}{|l|c|c|c|}
\hline \multicolumn{3}{|c|}{ Tablet Use } & \multicolumn{2}{c|}{ Ypecialty } & Yes & No & Total \\
\hline \multirow{3}{*}{ Mechanics and Mathematical Modeling } & 35 & 44 & 79 \\
\cline { 2 - 4 } & $44.3 \%$ & $55.7 \%$ & $100 \%$ \\
\cline { 2 - 4 } & $44.3 \%$ & $22.7 \%$ & $28.9 \%$ \\
\hline \multirow{3}{*}{ Management } & 32 & 64 & 96 \\
\cline { 2 - 4 } & $33.7 \%$ & $57 \%$ & $100 \%$ \\
\cline { 2 - 4 } Intelligent Systems in Humanities & $40.5 \%$ & $32.5 \%$ & $34.8 \%$ \\
\hline \multirow{3}{*}{ Total } & 12 & 87 & 99 \\
\cline { 2 - 4 } & $12.1 \%$ & $87.9 \%$ & $100 \%$ \\
\cline { 2 - 4 } & $15.2 \%$ & $44.8 \%$ & $36.3 \%$ \\
\cline { 2 - 4 } & 79 & 195 & 274 \\
\cline { 2 - 4 } & $28.9 \%$ & $71.1 \%$ & $100 \%$ \\
\hline
\end{tabular}

Source: developed by the authors.

The analysis of the time spent on learning with various mobile devices uncovered that, for the most part, during the 2015/2016 academic year, students used laptops (73.3\%) and tablets $(43.3 \%)$. Only the third position in this rating was taken by smartphones $(5.3 \%)$. However, due to the introduction of advanced technologies, today's smartphones became even smarter than ever. Given their convenience and strong hardware capabilities, now students tend to use smartphones much more often - their usage rate increased to $51.8 \%$. In this context, one can come to a decision that learners spend more time with the devices they use most in the teaching-learning process.

\section{Discussion}

In this day and age, mobile technologies are used more as a tool than as a teaching methodology. Based on a broad range of scientific literature on this matter, an assertion can be made that this technology alone does not lead to learning success. Notwithstanding this, when used as part of an effort to support active training, m-learning can increase student motivation, engagement, and learning efficiency. Online and mobile educational tools for mathematics can assist students' problem solving, enhance comprehension, provide representations of ideas and encourage general metacognitive abilities [4]. Online and mobile learning apps motivate students by making the course more enjoyable and interactive than traditional teaching methods. There is no doubt that more teaching services will emerge soon, creating a new educational model. Especially exciting is the research which presents e-learning and m-learning systems as a weighted directed graph where each node represents a course unit. To describe the structure of domain knowledge, including the learning goals, and all other available learning paths, this study has proposed a learning path graph (LPG) inscribed in a system prototype that implements adaptive learning path algorithms. The proposed algorithms use students' information from their profiles and their learning style to improve academic 
performance within an m-learning system that provides a suitable course content sequence in a personalized manner [32]. Many investigations are devoted to analyzing the capabilities of mobile applications that can advance learning and develop students' professional skills. Researchers have disclosed a close correlation between students' performance in language lessons, mathematics and index of verbal intelligence, index of intelligence practice, and a general index of intelligence [3]. Findings of the empirical study on the integration of an intelligent teaching system (Moso Teach) into an English curriculum suggest that an intelligent and adaptive learning platform combined with m-learning and well-designed activities can increase students' engagement in a wide variety of learning activities - from personalized learning to team collaboration [33].

Today, STEM education is undergoing a paradigm shift as teachers around the world are gradually moving from banning mobile devices to using them during lessons, lectures, lab practical's, and study trips [11]. Modern education poses many challenges to improve the quality of teaching and content knowledge, especially in such fields as science, technology, engineering, and mathematics. Researchers denote that the technological pedagogical content recognition system (TPACK) can be applied to increase the competence of STEM teachers. To improve TPACK for educators, scholars propose to use an m-learning system that personalizes digital learning content by analyzing learning styles, content attributes, as well as capabilities of a mobile device and network [34]. Several researchers have made an attempt to integrate STEM and TPACK framework as a means to advance education. Through the exploratory factor analysis, they have determined four factors that influence the effectiveness of STEM teachers. Among them are the technological pedagogical science knowledge, technological pedagogical mathematics knowledge, technological pedagogical engineering knowledge, and integrative STEM [35].

Some researchers propose to realize the strategic role of teaching science and mathematics by integrating games into the learning process. Not without reason, games successfully force people to spend time trying to achieve goals via a well-structured set of rules. Such well-structured rules also bound STEM domains. Thus, several educational games like MIT's Education Arcade have been developed with mobile devices in mind [36]. Such gamified learning is discovery-based and goal-oriented. It offers opportunities for collaboration and development of teamwork skills. Educational games can be used to teach interdisciplinary concepts in many complex scientific issues in a more engaging way than traditional methods. Besides, simulations and serious games allow students to recreate difficult situations to try new answers or pose creative solutions [20]. In order to outline the potential of mobile gaming in STEM education, scholars provide a systematic review of the research context, methodologies, measures, tools, and mobile game features [37]. This allows one to determine mobile gaming as a suitable approach to STEM education.

According to surveys, students use mobile phones during formal and informal education. At the same time, it is believed that these daily training activities can significantly contribute to understanding STEM as lifelong learning. Researchers note the positive influence of STEM Mobile Learning Package ecosystems on students' science and technology literacy [38]. 


\section{Conclusion}

As a relatively recent phenomenon in higher education, m-learning is very popular among students. Gradually it becomes a part of the current educational system. Mobile devices have the potential for learning embedded in everyday life since today their use is natural. The present research was conducted to understand differences in the use of mobile devices in higher education. The study covered students of three different specialties studying during two academic periods (2015/2016 and 2019/2020). The examination outcomes demonstrated a high increase in the application of mobile technologies in learning. It was determined that in the 2015/2016 academic year, the part of students using PDAs, tablets, smartphones, and laptops in the training process was $1 \%$, $34.3 \%, 10.4 \%$, and $90.1 \%$, respectively. During the $2019 / 2020$ period, the use of laptops grown to $91.3 \%$, and the share of smartphone users has increased unprecedentedly - to $61.5 \%$, while PDAs were deemed outdated and unused. This fact can be partially explained by the innovative functions of modern smartphones, which give one the opportunity to solve many diverse tasks simultaneously. They can easily load different Microsoft Office services, including Microsoft Word, Microsoft Excel, Microsoft PowerPoint, Microsoft Access and other applications that allow working not only with text files, but also databases, spreadsheets, and presentations anytime and anywhere. In this regard, using mobile technology for learning should raise some ethical issues and concerns as a limited ethical policy in the class that can be expressed in the requirements for mobile technologies used for studying (for example, requirements for smartphones). Among other possible challenges in Russian universities, the lack of local content for mobile educational applications, technical problems with wireless coverage, lack of proper preparation of educators, and equipment cost should also be noted. To ensure the spread of m-learning, the government, along with the university authorities, needs to overcome the above difficulties.

An analysis of the time a student spends on using various mobile devices in the learning process showed that in the 2015/2016 academic year, the smartphone usage rate constituted only 5.3\% and became more relevant in the 2019/2020 academic year $(51.8 \%)$.

The future work in this field may be focused on identifying and analyzing the implementation of mobile technologies and tools in the teaching process and their advantages and disadvantages in terms of methodological approaches to teaching.

Among the limitations of the study, it is worth noting the revealed differences in the use of smartphones and tablets according to the user's gender in the 2019/2020 academic year. It was observed that female students more often use smartphones and tablets than male ones. Nevertheless, this can be explained by different specialties. Traditionally, technical courses involve more men than women. For this reason, they are more tend to use specialized programs on laptops. In view of this, it seems interesting to study the use of mobile devices in learning in terms of their compliance with the needs of the curriculum and student's specialty.

The research findings may be beneficial for teachers and representatives of the administration of educational institutions. The higher education sector should be informed about trends in m-learning to support the use of mobile devices' capabilities. 


\section{$6 \quad$ References}

[1] Ryazantseva, M.V., Mikhaylova, N.V., Sokolovskiy, K.G., Kolomoets, E. N., Zatsarinnaya, E. I. (2020). Influence of ethnic origin, gender and religion on employment and labor relations. Opcion, 36(91): 11-24.

[2] Bharuthram, S., Kies, C. (2013). Introducing e-learning in a South African higher education institution: Challenges arising from an intervention and possible responses. British Journal of Educational Technology, 44(3): 410-420. https://doi.org/10.1111/j.1467$\underline{8535.2012 .01307 . \mathrm{x}}$

[3] Karabatzaki, Z., Stathopoulou, A., Kokkalia, G., Dimitriou, E., Loukeri, P.I., Economou, A., Drigas, A. (2018). Mobile Application Tools for Students in Secondary Education. An Evaluation Study. International Journal of Interactive Mobile Technologies, 12(2): 142-161. https://doi.org/10.3991/ijim.v12i2.8158

[4] Sadovnikova, N.O., Mirzaahmedov, A.M. (2019). Relevant concepts of a teacher's state when experiencing professional identity crisis. The Education and science journal. 21(2): 113-131. (In Russian). https://doi.org/10.17853/1994-5639-2019-2-113-131

[5] Ariffin, S.A. (2014), The Contribution of mobile learning to the Study of Local Culture in the Malaysian University Context. PhD dissertation, Faculty of Engineering and Information Technology, University of Technology Sydney, Sydney, Australia.

[6] Darmawan, D., Suryadi, E., Wahyudin, D. (2016). Smart Digital for Mobile Communication Through TVUPI Streaming for Higher Education. International Journal of Interactive Mobile Technologies, 13(5): 30-46. https://doi.org/10.3991/ijim.v13i05.10286

[7] Sarrab, M., Al-Shihi, H., Rehman, O.M.H. (2013). Exploring major challenges and benefits of m-learning adoption. British Journal of Applied Science and Technology, 3(4): 826-839. https://doi.org/10.9734/bjast/2013/3766

[8] Zidoun, Y., El arroum, F.-Z., Talea, M., Dehbi, R. (2016). Students' Perception About Mobile Learning in Morocco: Survey Analysis. International Journal of Interactive Mobile Technologies, 10(4): 80-84. https://doi.org/10.3991/ijim.v10i4.5947

[9] Su, C.H., Cheng, C.H. (2015). A mobile gamification learning system for improving the learning motivation and achievements. Journal of Computer Assisted Learning, 31(3): 268286. https://doi.org/10.1111/jcal.12088

[10] Ramírez-Donoso, L., Pérez-Sanagustín, M., Neyem, A. (2018). My MOOC Space: Mobile cloud-based system tool to improve collaboration and preparation of group assessments in traditional engineering courses in higher education. Computer Applications in Engineering Education, 26(5): 1507-1518. https://doi.org/10.1002/cae.22045

[11] Crompton, H., Burke, D., Gregory, K.H. (2017). The use of mobile learning in PK-12 education: A systematic review. Computers \& Education, 110: 51-63. https://doi.org/10. 1016/j.compedu.2017.03.013

[12] Ibáñez, M.-B., Delgado-Kloos, C. (2018). Augmented reality for STEM learning: A systematic review. Computers \& Education, 123: 109-123. https://doi.org/10.1016/j.compe du.2018.05.002

[13] Marinakou, E., Giousmpasoglou, C. (2015). M-learning in the Middle East: The case of Bahrain. In Assessing the role of mobile technologies and distance learning in higher education. IGI Global, pp. 176-199. https://doi.org/10.4018/978-1-4666-7316-8.ch008

[14] Bano, M., Zowghi, D., Kearney, M., Schuck, S., Aubusson, P. (2018). Mobile learning for science and mathematics school education: A systematic review of empirical evidence. Computers \& Education, 121: 30-58. https://doi.org/10.1016/j.compedu.2018.02.006

[15] Embi, M.A., Nordin, N.M. (2013). Mobile learning: Malaysian initiatives and research findings. Centre for Academic Advancement, University Kembangan Malaysia, Malaysia. https://doi.org/10.21315/mjde2015.17.2.1

[16] Darmaji, D., Kurniawan, D., Astalini, A., Lumbantoruan, A., Samosir, S. (2019). Mobile Learning in Higher Education for The Industrial Revolution 4.0: Perception and Response 
of Physics Practicum. International Journal of Information Management, 13(9): 4-20. https://doi.org/10.3991/ijim.v13i09.10948

[17] Sad, S.N., Goktas, O. (2013). Preservice teachers' perceptions about using mobile phones and laptops in education as mobile learning tools. British Journal of Educational Technology, 45(4): 606-618. https://doi.org/10.1111/bjet.12064

[18] Göksu, İ., Atici, B. (2013). Need for mobile learning: technologies and opportunities. Procedia-Social and Behavioral Sciences, 103: 685-694. https://doi.org/10.1016/j.sbspro.20 13.10 .388

[19] Juric, P., Bakaric, M.B., Matetic, M. (2018). Design and implementation of anonymized social network-based mobile game system for learning mathematics. International Journal of Emerging Technologies in Learning, 13(12): 83-98. https://doi.org/10.3991/ijet.v13i $\underline{12.8762}$

[20] Eichler, M.L., Perry, G.T., Lucchesi, I.L., Melendez, T.T. (2018). Mobile Game-Based Learning in STEM Subjects. In Encyclopedia of Information Science and Technology, Fourth Edition. IGI Global, pp. 6376-6387. https://doi.org/10.4018/978-1-5225-2255$\underline{3 . c h 554}$

[21] Ariffin, S.A., Sidek, S.F., Mutalib, M.F.H. (2018). A Preliminary Investigation of Malaysian Student's Daily Use of Mobile Devices as Potential Tools for STEM in a Local University Context. International Journal of Interactive Mobile Technologies, 12(2): 80-91. https://doi.org/10.3991/ijim.v12i2.8015

[22] Cheon, S.H., Reeve, J. (2015). A classroom-based intervention to help teachers decrease students' amotivation. Contemporary Educational Psychology, 40: 99-111. https://doi. org/10.1016/j.cedpsych.2014.06.004

[23] Eskin, S., Bachnak, R., Wirick, D. (2018). A Summer Enrichment Program to Prepare Students for STEM Majors in College. In Proceedings of the 2018 Conference for Industry and Education Collaboration, Vol. 2, pp. 7-12.

[24] Hu, A., Hibel, J. (2015). Where Do STEM Majors Lose Their Advantage? Contextualizing Horizontal Stratification of Higher Education in Urban China. Research in Social Stratification and Mobility, 41: 66-78. https://doi.org/10.1016/j.rssm.2015.05.004

[25] Khaeroningtyas, N., Permanasari, A., Hamidah, I. (2016). STEM Learning in Material of Temperature and its Change to Improve Scientific Literacy of Junior High School. Jurnal Pendidikan IPA Indonesia, 5(1): 94-100.

[26] Goldhaber, D., Gratz, T., Theobald, R. (2017). What's in a Teacher Test? Assessing the Relationship between Teacher Licensure Test Scores and Student STEM Achievement and Course-Taking. Economics of Education Review, 61: 112-129. https://doi.org/10.1016/j .econedurev.2017.09.002

[27] Arrifin, S.A., Yatim, M.H.M., Zaibon, S.B., Ali, A.Z.M., Ibrahim, A.B., Sidek, S.F., Muttalib, M.F.H.A. (2018). An Investigation of Student Experience of STEM Mobile Learning in a Local Malaysian University. In World Conference on Mobile and Contextual Learning, pp. 36-50.

[28] Crompton, H., Traxler, J. (2015). Mobile learning and STEM: Case studies in practice. Routledge. New York.

[29] Kalogiannakis, M., Papadakis, S. (2020). The Use of Developmentally Mobile Applications for Preparing Pre-Service Teachers to Promote STEM Activities in Preschool Classrooms. In Mobile Learning Applications in Early Childhood Education. IGI Global, pp. 82-100. https://doi.org/10.4018/978-1-7998-1486-3.ch005

[30] Batterton, K.A., Hale, K.N. (2017). The Likert scale what it is and how to use it. Phalanx, 50(2): 32-39.

[31] Sharpe, D. (2015). Chi-Square Test is Statistically Significant: Now What? Practical Assessment, Research, and Evaluation, 20(1): 8 .

[32] Alshalabi, I.A., Hamada, S.E., Elleithy, K.M., Badara, J.A., Moslehpour, S. (2018). Automated Adaptive Mobile Learning System using Shortest Path Algorithm and Learning Style. 
International Journal of Interactive Mobile Technologies, 12(5): 4-27. https://do i.org/10.3991/ijim.v12i5.8186

[33] Zhu, Q., Wang, M. (2020). Team-based mobile learning supported by an intelligent system: case study of STEM students. Interactive Learning Environments, 28(5): 543-559. https://doi.org/10.1080/10494820.2019.1696838

[34] Kajonmanee, T., Chaipidech, P., Srisawasdi, N., Chaipah, K. (2020). A personalised mobile learning system for promoting STEM discipline teachers' TPACK development. International Journal of Mobile Learning and Organisation, 14(2): 215-235. https://doi. org/10.1504/ijmlo.2020.10026336

[35] Chai, C.S., Jong, M., Yan, Z. (2020). Surveying Chinese teachers' technological pedagogical STEM knowledge: a pilot validation of STEM-TPACK survey. International Journal of Mobile Learning and Organization, 14(2): 203-214. https://doi.org/10.1504/ijmlo.2020.1 $\underline{0026335}$

[36] Johnson, L., Adams Becker, S., Estrada, V., Martín, S. (2013). Technology Outlook for STEM+Education 2013-2018: An NMC Horizon Project Sector Analysis. The New Media Consortium, Austin, TX.

[37] Gao, F., Li, L., Sun, Y. (2020). A systematic review of mobile game-based learning in STEM education. Educational Technology Research and Development, 1: 1-37.

[38] Ngabekti, S., Prasetyo, A.P.B., Hardianti, R.D., Team panpong, J. (2019). The development of stem mobile learning package ecosystem. Journal Pendidikan IPA Indonesia, 8(1): 81-88. https://doi.org/10.18502/kss.v3i18.4751

\section{$7 \quad$ Authors}

Shchedrina Elena Vladimirovna is a $\mathrm{PhD}$, Associate Professor of the Department of Information Technologies in the AIC, Russian State Agricultural University - Moscow Agricultural Academy named after K.A. Timiryazev, Moscow, Russia. Email: shchedrinae154@rambler.ru, shchedrina@rgau-msha.ru

Galkina Elena Nikolaevna is a PhD, Associate Professor of the Department of Medical Informatics and Statistics, I.M. Sechenov First Moscow State Medical University, Moscow, Russia.

Petunina Irina Aleksandrovna is a $\mathrm{PhD}$, Associate Professor of the Department of Higher Mathematics, Federal State Budgetary Educational Institution of Higher Education "Kuban State Agrarian University named after I.T. Trubilin", Krasnodar, Russia.

Lushkov Richard Mikhailovich is a Lecturer of the Department of Orthopedic Dentistry of the Institute of Dentistry named after E.V. Borovsky, I.M. Sechenov First Moscow State Medical University, Moscow, Russia.

Article submitted 2020-09-12. Resubmitted 2020-10-26. Final acceptance 2020-10-26. Final version published as submitted by the authors. 